Research Article

\title{
Strength Characteristics of Cement Treated and Expanded Polystyrene Mixed Lightweight of Waste Soil from the Construction Site of a Yangtze River Bridge in China
}

\author{
Weihua Lu $\mathbb{D}^{1,2,3}$ Jianyun Wang, ${ }^{1,2,3}$ and Yongxing Zhang ${ }^{1,2,3}$ \\ ${ }^{1}$ School of Civil Engineering, Nanjing Forestry University, Nanjing, Jiangsu 210037, China \\ ${ }^{2}$ National-Local Joint Laboratory of Engineering Technology for Long-term Performance enhancement of Bridges in \\ Southern District, Changsha University of Science \& Technology, Changsha 410114, Hunan, China \\ ${ }^{3}$ Key Laboratory of Road Structure and Material of Ministry of Transport (Changsha), \\ Changsha University of Science \& Technology, Changsha 410114, Hunan, China \\ Correspondence should be addressed to Weihua Lu; whlnjfu@njfu.edu.cn
}

Received 11 February 2020; Accepted 11 May 2020; Published 27 May 2020

Academic Editor: Fan Gu

Copyright (c) 2020 Weihua Lu et al. This is an open access article distributed under the Creative Commons Attribution License, which permits unrestricted use, distribution, and reproduction in any medium, provided the original work is properly cited.

In the past decades, the speed and scale of Chinese infrastructure construction have been enormous, and the resulting construction waste is also quite amazing, which has become a huge threat to environmental protection. If the pollution-free engineering utilization of the construction waste can be achieved at a low cost, it will undoubtedly be a great benefit for the country and the people. Therefore, a preliminary experimental study was conducted to investigate the strength characteristics of the cement treated and expanded polystyrene mixed lightweight. The waste soil (muddy clay and fine sand) as the main component of the lightweight mixture is taken from a foundation construction site of a Yangtze River Bridge which connects two eastern coastal cities, Zhenjiang and Yangzhou. With different mixture ratios and additives of the cement treated and expanded polystyrene mixed lightweight, a series of cubic samples were tested by the unconfined compressive strength test, and collections of standard cylinder samples prepared by hand were inspected by the conventional triaxial shear test. Then, a good exponential relationship between the uniaxial compressive strength and the cement mixing ration was founded, and a logarithmic relationship was captured between the compressive strength and curing time within a period of 28 days after the specimens were made. Samples made of different soil as raw materials have different strengths, but all of these specimens show a strain-hardening and stable behavior. Results show that the mechanical strength characteristics of the cement treated and expanded polystyrene mixed waste soil mainly depend on the proportions of lightweight mixture.

\section{Introduction}

With the development of urbanization in China, the construction industry develops rapidly. However, the growth of construction industry is accompanied by the production of construction waste, such as abandoned cement concrete, brick, wood, metal, and excavated soil $[1,2]$. Therefore, it will become very social and economic value if people can achieve the resource utilization of those aforementioned wastes. Comparatively, excavated soil needs more enough sites to stack and is more likely to produce potentially harmful pollution to the environment. In the process of recycling the waste soil, it is generally accepted that adding some curing agents or modified materials, such as cement ash or lime powder, can play a good stabilizing role in reducing the harmfulness [3]. Sometimes light materials such as expanded polystyrene particles are also added for mixing to reduce the mixture weight, so as to achieve the purpose of reducing the self-weight in some earthworks, such as airport runway, highway embankment, and railway embankment $[4,5]$. On the one hand, the engineering characteristics of waste soil have been improved due to the solidification with cement, and on the other hand, the settlement of the embankment has also been controlled due to the lightweight treatment $[6,7]$. In engineering, the cement treated and expanded polystyrene mixed lightweight is often used as the 
subgrade filler of adjacent projects, and the subgrade bears the vehicle load transmitted from the pavement layer and the self-weight load of the upper structure. Therefore, the strength and deformation characteristics of subgrade have a significant influence on the global strength and the stiffness of subgrade and the pavement structure.

As a result, the mechanical properties of the artificially lightweight mixture need to be revealed and quantified. Since Frydenlund [8] investigated the application of EPS geofoam in an embankment fill over soft clay foundation in Norway, more studies have been conducted in the past decades to reveal the mechanical properties of lightweight mixtures. Some focused on influencing factors such as cement content, water content, curing time, and volume ratio. Then, the parametric sensitivity on strength of cemented lightweight mixture would be revealed $[9,10]$. In addition, there were also some studies focusing on the change of soil properties caused by additives, such as unit weight, liquid limit, and plastic index [11]. Some preliminary quantitative relations obtained from the test were also well applied in the project [12-14]. With the help of some high-tech equipment, the strength mechanism of the microstructure of lightweight mixture can be explained and quantified more easily $[15,16]$. Moreover, the mechanical constitutive model of the lightweight mixture can also be established, and the prediction of strength and deformation of these lightweight fillers have a good guiding role in engineering application [17-19]. However, these current research studies are mainly based on ideal conditions. The practical experience of using waste soil after lightweight treatment is not enough, and systematic test data or comparative effect analysis is still not sufficient.

In this study, two strength test methods will be carried out to investigate the strength characteristics of the cement treated and expanded polystyrene mixed lightweight of waste soil from a pile construction site of a Yangtze River Bridge which connects two eastern coastal cities, Zhenjiang and Yangzhou, in China. One is the unconfined compressive strength test, and the other is the conventional triaxial shear test. Before the test, a series of attempts were also made on the conditions of proportioning via the conventional compaction test. Under certain conditions, the strength change rule of the sample is revealed, and the quantitative relationship of the influencing factors is preliminarily established. This study will become an important reference for engineers and researchers interested in the design, construction, and performance of lightweight materials.

\section{Lightweight Treatment and Proportioning Study}

2.1. The Waste Soil and Additives. The waste soil was taken from a pile construction site of the Taizhou Bridge, a suspension bridge across the river, which connects two medium-sized cities, Zhenjiang and Yangzhou, both of which are located in the plain of the lower reaches of the Yangtze River in China. Except that the two main piers are in the center of the river, most of the approach bridge and the transition section between road and bridge are located on the river bank. Coupled with the area of cable anchorage on both sides of the bank, the volume of waste soil produced is very large. According to the field site conditions, the waste soil is mainly composed of two kinds of soil materials: one is muddy clay and the other is hydraulic fill sand. On the other hand, due to the elevation change of ramp and transition section, a lot of subgrade filling will be required in the later stage. Therefore, it will be a very economic and environmental protection achievement to reuse these waste soils.

In the laboratory, the average natural water content of the muddy clay taken from the construction site is $52 \%$, and the natural density is about $1.75 \mathrm{~g} / \mathrm{cm}^{3}$. The liquid and plastic limits are $44 \%$ and $23 \%$, respectively. According to the ASTM D2487-11 [20], the waste muddy soil belongs to the clay with low liquid limit. Another waste soil is the sand, the content of the part whose particle size is smaller than $0.075 \mathrm{~mm}$ is not more than $5 \%$, and the content of the part whose particle size is larger than $0.25 \mathrm{~mm}$ is not more than $4 \%$. Its nonuniformity coefficient and curvature coefficient are 1.4 and 0.7 , respectively. Obviously, the grading of this fine sand soil is poor. The particle grading curve of the two waste soils is shown in Figure 1.

In order to improve their mechanical properties and achieve the purpose of lightweight utilization, the Portland cement, the tap water, and the expanded polystyrene beads (EPS) are added in a certain proportion and order, with a specific volume ratio or weight ratio. Detailed information of the ordinary Portland cement is shown in Table 1. The EPS beads are white and round, with the diameters varying from 2 to $3 \mathrm{~mm}$, and the bulk unit weight of which is $0.013 \mathrm{~g} / \mathrm{cm}^{3}$.

\subsection{The Lightweight Proportion and the Compaction Test.} The unit weight of the cement treated and expanded polystyrene mixed lightweight mainly depends on the amount of EPS beads, i.e., the volume ratio of soil to light particles. Meanwhile, the bearing layer made of these mixtures should have enough potential strength and stiffness. Therefore, the Portland cement added by weight percentage plays an important role in bonding EPS beads and raw waste soil particles as a mixture. Through preliminary attempts and referencing to current literature studies, two volume ratios of waste soil to EPS beads, $V_{s}$ : $V_{E}=50: 50$ and $45: 55$, respectively, are selected, and different cement contents at $\alpha_{w}=8,10,12$, and $15 \%$ are tested to evaluate the lightweight strength properties. Based on the standard curing conditions, four curing times of $7,14,28$, and 90 days are selected to evaluate the development of strength growth.

Compaction shortens the distance between particles and increases the density and strength of the lightweight mixture. Engineering application requires that the lightweight density should be reduced as much as possible on the premise of ensuring the strength. With the help of the heavy compaction test, the maximum dry density $\left(\rho_{d \max }\right)$ and the optimum moisture content $\left(w_{o p}\right)$ of the lightweight waste soil under a compaction work will be obtained. In a cylindrical vessel with an internal diameter of $10 \mathrm{~cm}$ and a height of $12.7 \mathrm{~cm}$, the mixture with a certain weight was compacted by three layers, each with fourteen compaction 


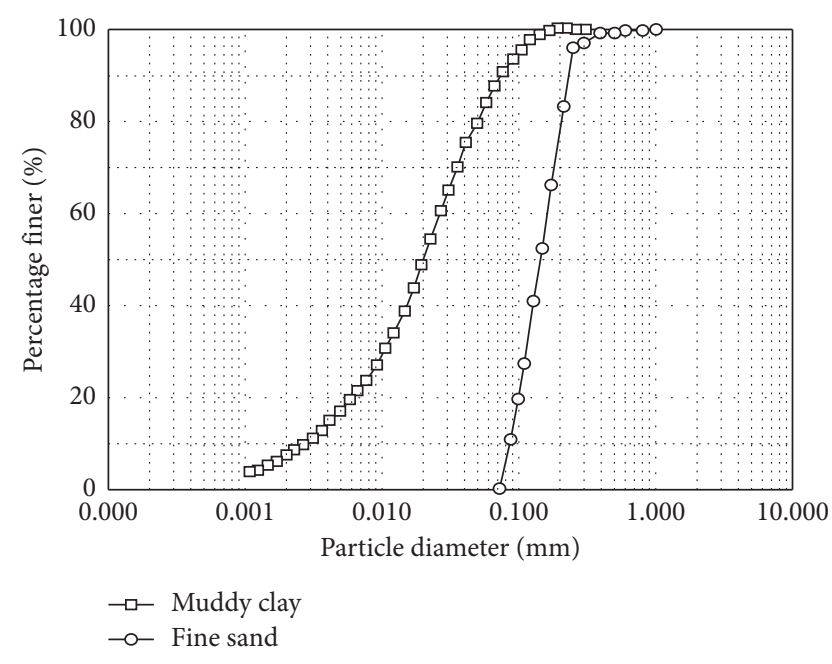

Figure 1: Particle grading analysis curve for muddy clay and fine sand.

Table 1: Properties of the ordinary Portland cement.

\begin{tabular}{lcc}
\hline Items & Unit & Values \\
\hline Density & $\mathrm{g} / \mathrm{cm}^{3}$ & 1.3 \\
Fineness (residue on 0.08 mm sieve) & $\%$ & 2.50 \\
Normal consistency & $\%$ & 25.2 \\
Setting time & Minutes & 155 \\
$\quad$ Initial time & & 230 \\
$\quad$ Final time & & \\
Strength of cement mortar (ISO) & & 3.8 \\
$\quad$ 3 d fracture resistance & $\mathrm{MPa}$ & 8.0 \\
28d fracture resistance & & 16.0 \\
3d compression strength & & 42.0 \\
28 d compression strength & & 2.17 \\
$\mathrm{SO}_{3}$ content & $\%$ & 4.2 \\
$\mathrm{MgO}^{2}$ content & & 1.2 \\
Ignition loss & &
\end{tabular}

times. The weight of the hammer is $4.5 \mathrm{~kg}$ and the height of drop is $45 \mathrm{~cm}$, with the total compaction work less than $860 \mathrm{~kJ} / \mathrm{m}^{3}$. The detailed information of each composition and the compaction test fitting curves are shown in Figure 2. Ideally, a peak value can be found for each case, and this is of important potential filling function for the subgrade filler.

Table 2 shows the results of the compaction test. It is obvious that the addition amount of the EPS beads has a decisive effect on the maximum dry density of the lightweight mixture. Though the maximum dry density decreases with the increase of EPS particles, the change of the optimum moisture content is not clear. However, the influence of cement content on the maximum dry density and the optimum moisture content is not obvious. This may be because the amount of cement added is not enough to have a fatal effect on the composition of the lightweight mixture, which is helpful for paving control according to the amount of cement added at a certain level during the site filling construction. With the same volume ratio and cement content, the optimal moisture content for muddy clay lightweight is at least $30 \%$ higher than that of the sand lightweight, while the maximum dry density of the former is slightly smaller than that of the latter.

\section{Results and Discussion}

3.1. Unconfined Compression Test. In the design and construction of EPS lightweight subgrade fill, the compressive strength is a very important index and is related to the safety of the project. The compressive strength is obtained from the compaction test in which the samples are not subject to lateral pressure. A series of cubic samples with the size of $7 \mathrm{~cm} \times 7 \mathrm{~cm} \times 7 \mathrm{~cm}$ are prepared using the aforementioned densities and water contents. Each specimen was compacted in three layers, and the sample together with mould was placed in the curing room for 24 hours before demoulding. Then, these samples were cured to the required period. In a standard curing room, the temperature was kept at a temperature of about $20 \pm 2^{\circ} \mathrm{C}$, with the relative humidity over $95 \%$. When testing, an axial loading device controlled by computer was used to compact these samples, with a displacement control rate of $1.0 \mathrm{~mm}$ per minute. There were at least 5 parallel samples for each mixture ratio, and the singular data were eliminated. When the stress-strain curve reached a peak value, it was determined as the compressive strength of the sample. If there was no peak value or the peak value was not obvious, the stress at $15 \%$ of the axial strain was taken. In order to study the influence of cement more sufficient, six cement contents were selected, e.g., 8, 10, 12, 15,18 , and $20 \%$.

Figure 3(a) shows the variation of unconfined compressive strength due to cement content increase and volume ratio change. For specimens with a curing time of 7 days, the unconfined compressive strength has a good exponential relationship with the cement content. The same condition is also applied to the case of the 28-day curing time. The exponential relation can be summed up as a unified function form, and the unconfined compressive strength can be formulated as $q_{\max }=A e^{B \alpha_{c}}$, where $A$ and $B$ are the fitting parameters. Based on the data range of the test results, $A$ is between 70 and 270 and $B$ is between 0.1 and 6.5, and they are mainly affected by the EPS addition, the curing time, the soil category, and the curing condition. Figure 3(b) shows that the strength difference gaps increase with increasing cement content for all cases. This indicates that cement has a decisive effect on the strength of lightweight mixtures.

The increase of EPS particles has a decreasing effect on the compressive strength of the lightweight mixture. The most likely explanation is that the original part occupied by hydrate is replaced by the increased EPS beads. In terms of composition, due to the increase of light particles, the porosity of light mixture is increased and the strength is reduced. When the cement content is relatively low, the compressive strength of the lightweight with different EPS particles has a small difference. But when the cement content is high, the difference cannot be ignored. In other words, the increase of cement content enlarges the influence of EPS beads on the strength reduction of the lightweight mixture, that is to say, it reduces the effect of cement hydrate. 


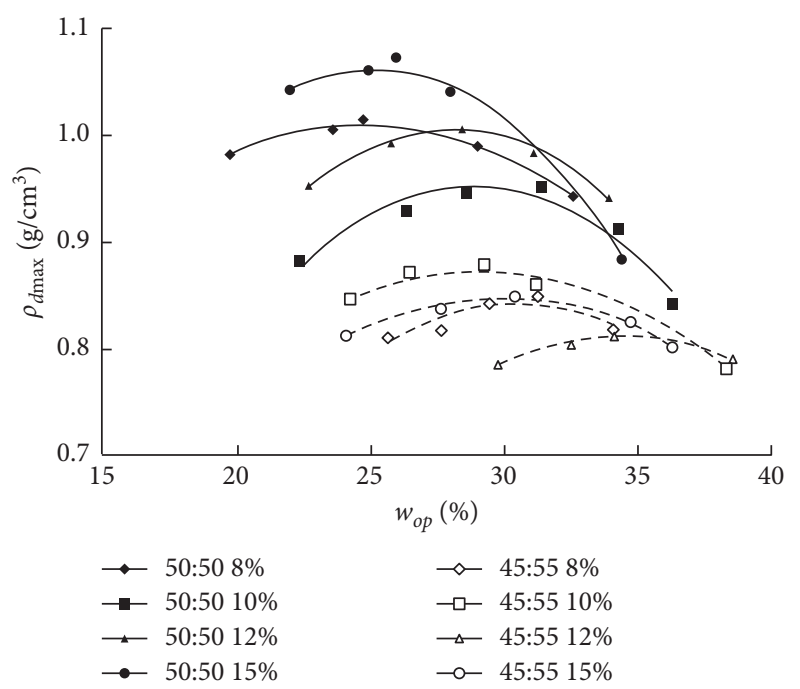

(a)

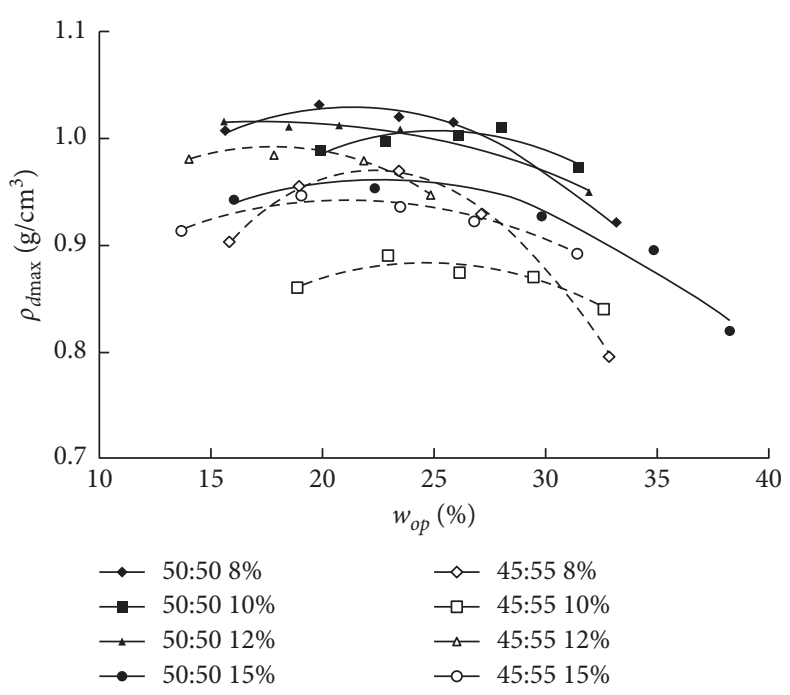

(b)

Figure 2: Results of compaction test and fitting curves: (a) muddy clay and (b) fine sand.

TABLE 2: Results of the compaction test.

\begin{tabular}{|c|c|c|c|c|c|c|c|c|c|c|c|c|c|c|c|c|}
\hline \multirow{3}{*}{$\begin{array}{l}\text { Waste soil } \\
V_{s}: V_{E} \\
\alpha_{c}(\%)\end{array}$} & \multicolumn{8}{|c|}{ Muddy clay } & \multicolumn{8}{|c|}{ Fine sand } \\
\hline & \multicolumn{4}{|c|}{$50: 50$} & \multicolumn{4}{|c|}{$45: 55$} & \multicolumn{4}{|c|}{$50: 50$} & \multicolumn{4}{|c|}{$45: 55$} \\
\hline & 8 & 10 & 12 & 15 & 8 & 10 & 12 & 15 & 8 & 10 & 12 & 15 & 8 & 10 & 12 & 15 \\
\hline$\rho_{d \max }\left(\mathrm{g} / \mathrm{cm}^{3}\right)$ & 1.01 & 0.98 & 0.98 & 1.04 & 0.86 & 0.83 & 0.82 & 0.86 & 1.04 & 1.01 & 1.02 & 0.98 & 0.97 & 0.91 & 0.98 & 0.96 \\
\hline$w_{o p}(\%)$ & 24.8 & 29.4 & 27.5 & 24.7 & 30.8 & 27.8 & 34.4 & 30.5 & 17.6 & 20.1 & 15.8 & 16.4 & 18.2 & 18.4 & 14.9 & 13.0 \\
\hline
\end{tabular}

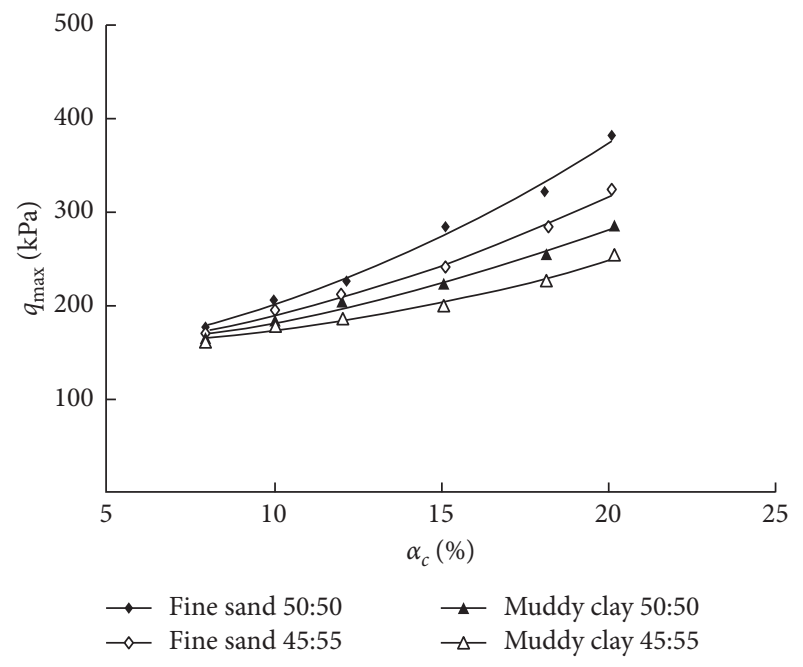

(a)

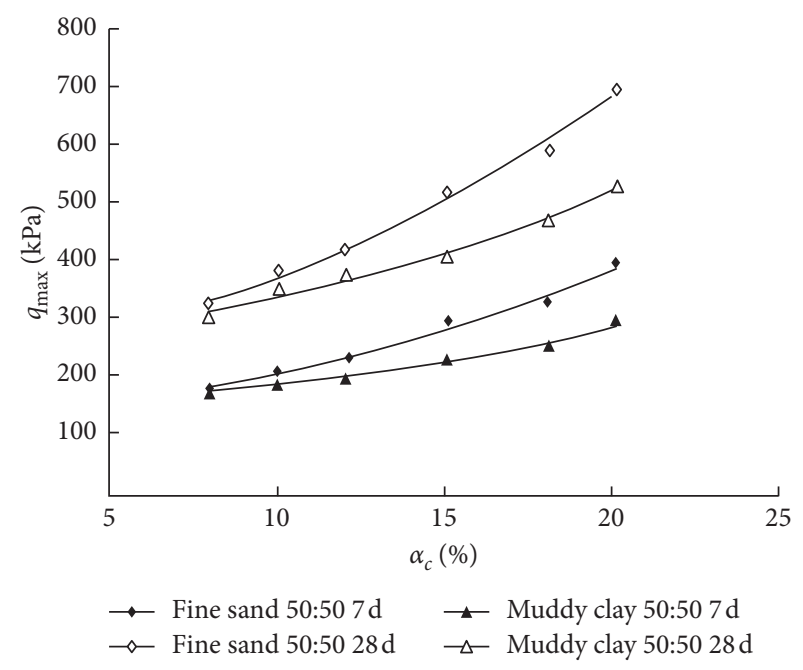

(b)

Figure 3: Unconfined compressive strength for (a) different volume ratios and (b) curing times.

As the hydration of cement takes time, the curing period has a significant effect on the strength of the lightweight mixture. Figure 4 shows the increase of unconfined compressive strength of two proportions versus the increasing curing time. In general, the unconfined compressive strength increases with increasing curing time. Similar to the ordinary concrete products, the early strength of waste soil lightweight mixture is greatly affected by curing time, and the original 28 days is very important for the strength growth. Obviously, strength increase is not significant after 


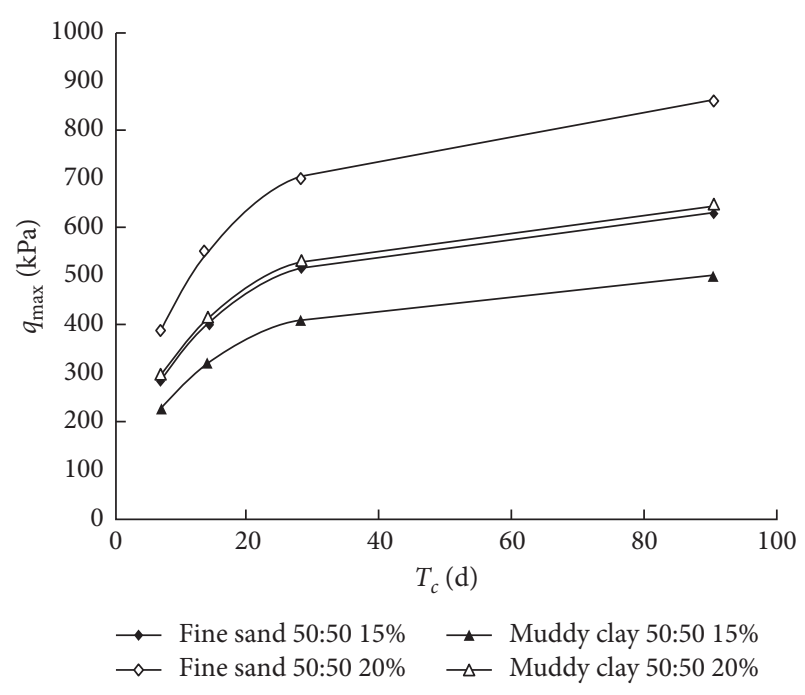

FIGURE 4: Influence of curing time on compressive strength.

28 days and the entire relation between the unconfined compressive strength and the curing time is close to a logarithmic function, and the difference lies in the different influence coefficients.

The unconfined compressive strength of the artificially prepared lightweight mixture produced by different waste soil properties is different. From the aforementioned analysis, it can be seen that the compressive strength of sand lightweight is greater than that of muddy clay lightweight. For the 7-day curing time case, the comparison of unconfined compressive strength of the two waste soils is illustrated in Table 3. Therefore, the difference in mineral composition and grading composition of different raw soils, the different conditions for cement hydration reaction, and the different structures of EPS particle cementation will have a huge impact on the properties of lightweight mixture.

3.2. Conventional Triaxial Test. Shear strength is one of the most important mechanical properties of the geotechnical materials. Whether the shear strength of geotechnical materials can be correctly measured is often the key to the quality of the engineering design and the success or failure of the project. Because the triaxial test can simulate the actual stress state of materials better, the shear strength indexes of internal friction angle $(\varphi)$ and the cohesion $(c)$ obtained by this method perform more effective than other test methods. Considering the time of the test and the actual state of the lightweight filler in situ, it is more appropriate to determine the index by the consolidated undrained test (CU). Furthermore, because the pore pressure of the specimen in the shear process can be measured, the effective stress strength index can be obtained. In Table 4, the unconsolidated undrained test (CU) scheme of this study is illustrated and four influence factors are evaluated.

The samples are made with the help of a mini compactor, with a standard uniform size of $3.91 \mathrm{~cm}$ in diameter and $8 \mathrm{~cm}$ in height. For each cell pressure and proportion case, three parallel samples will be tested and the average value is
TABle 3: Comparison of different waste soil lightweight (7 days).

\begin{tabular}{lccc}
\hline $\begin{array}{l}\alpha_{c} \\
(\%)\end{array}$ & $\begin{array}{c}\text { Fine sand } \\
\text { lightweight }\end{array}$ & $\begin{array}{c}\text { Waste soil } \\
\text { Muddy clay } \\
\text { lightweight }\end{array}$ & $\begin{array}{c}\text { Increment } \\
(\%)\end{array}$ \\
\hline 8 & 173.0 & 164.3 & 5.3 \\
10 & 204.8 & 185.7 & 10.3 \\
12 & 225.9 & 198.2 & 14.0 \\
15 & 271.3 & 226.6 & 19.7 \\
18 & 319.7 & 252.5 & 26.6 \\
20 & 368.3 & 280.1 & 31.5 \\
\hline
\end{tabular}

Table 4: The CU test scheme.

\begin{tabular}{lc}
\hline Waste soil & Muddy clay \\
\hline$V_{s}: V_{E}$ & $50: 50$ and $45: 55$ \\
$\alpha_{c}(\%)$ & 14 and 16 \\
$T_{c}$ (curing time, d) & 7,14 and 28 \\
$\sigma_{3}$ (cell pressures, $\left.\mathrm{kPa}\right)$ & 50,100 and 200 \\
\hline
\end{tabular}

adopted, unless there is one abnormal data to be removed. Before the shear test, the saturation of the sample shall be checked by the back-pressure method until it reaches $98 \%$, and the pore pressure valve should be closed after consolidation. Similar to the unconfined compressive test, the CU test is also conducted by the displacement control rate of $0.08 \mathrm{~mm} / \mathrm{min}$. When the shear test starts, the pore water pressure should be recorded, and this will provide data for the analysis of effective stress later.

For the volume ratio of $V_{s}: V_{E}=45: 55$ and the cement content of $\alpha_{c}=16 \%$, the consolidated undrained shear stressstrain curve, the Mohr failure circle, and its shear strength envelope at a curing time of 7 days can be illustrated in Figure 5. It is obvious that the stress-strain curves all belong to the strain hardening type, and a common tangent line under different confining pressures can be obtained. The intercept on the ordinate is the cohesion of the specimen, and the inclination of the diagonal is the angle of internal friction. Coincidentally, the appropriate strength envelope can be found under three different confining pressures for each proportion, which is very helpful to determine the shear strength index of the lightweight.

Table 5 illustrates the test results of all samples of the CU test. Overall, the effective stress cohesion is smaller than the total stress cohesion, while the effective internal friction angle is larger than the total stress internal friction angle. The strength parameters of the fine sand lightweight are larger than those of the muddy clay lightweight. In general, both the total stress strength index and the effective stress strength index will increase with the increase of cement content and with the extension of curing time, but decrease with the increase of EPS particles. The main reason is that with the increase of EPS particles, the relative content of cementitious material in the lightweight mixture is reduced. That is to say, under the action of external force, the effect of the agglomeration component in this material is weakened. At the same time, the increase of EPS particles makes the cementation structure easier to be destroyed and the damaged area enlarged due to the stress concentration in the sample. 


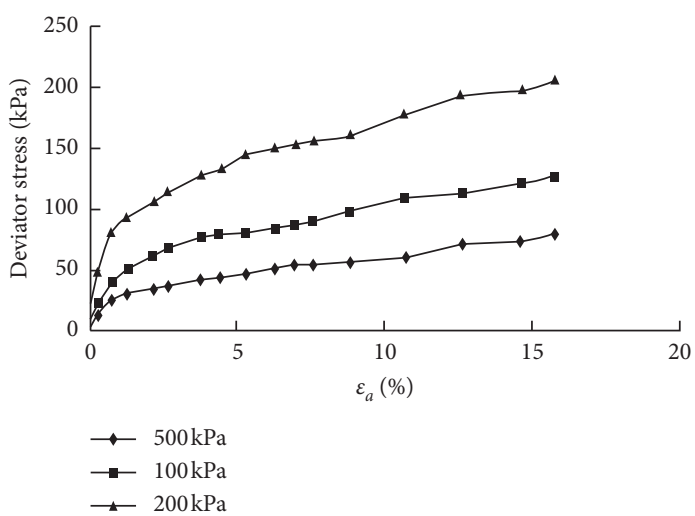

(a)

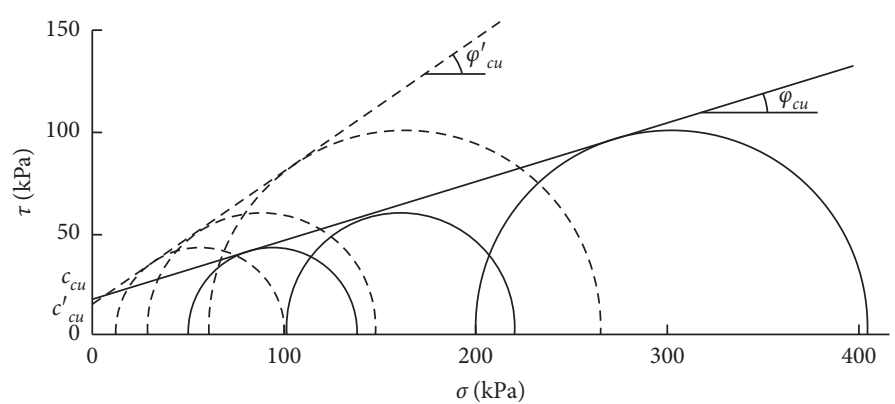

(b)

FIGURE 5: Shear strength test of the muddy clay lightweight: (a) stress-strain curve; (b) failure envelope of the lightweight $\left(V_{s}: V_{E}=45: 55\right.$, $\alpha_{c}=16 \%$, and $\left.T_{c}=7 \mathrm{~d}\right)$.

TABle 5: Comparison of the CU test results for different proportions.

\begin{tabular}{|c|c|c|c|c|c|c|c|c|c|}
\hline \multirow{3}{*}{$T_{c}(\mathrm{~d})$} & \multirow{3}{*}{ Strength index } & \multicolumn{4}{|c|}{ Fine sand } & \multicolumn{4}{|c|}{ Muddy clay } \\
\hline & & \multicolumn{2}{|c|}{$V_{s}: V_{E}=45: 55$} & \multicolumn{2}{|c|}{$V_{s}: V_{E}=50: 50$} & \multicolumn{2}{|c|}{$V_{s}: V_{E}=45: 55$} & \multicolumn{2}{|c|}{$V_{s}: V_{E}=50: 50$} \\
\hline & & $\alpha_{c}=14 \%$ & $\alpha_{c}=16 \%$ & $\alpha_{c}=14 \%$ & $\alpha_{c}=16 \%$ & $\alpha_{c}=14 \%$ & $\alpha_{c}=16 \%$ & $\alpha_{c}=14 \%$ & $\alpha_{c}=16 \%$ \\
\hline \multirow{4}{*}{7} & $c_{c u}(\mathrm{kPa})$ & 16.72 & 25.11 & 18.22 & 27.34 & 15.50 & 23.79 & 16.97 & 25.50 \\
\hline & $c_{c u}^{\prime}(\mathrm{kPa})$ & 14.91 & 22.04 & 16.23 & 24.69 & 13.69 & 20.31 & 14.44 & 22.91 \\
\hline & $\varphi_{c u}\left({ }^{\circ}\right)$ & 16.27 & 18.26 & 17.14 & 19.58 & 14.39 & 17.52 & 15.20 & 19.02 \\
\hline & $\varphi_{c u}^{\prime}\left({ }^{\circ}\right)$ & 33.73 & 34.33 & 42.98 & 43.74 & 32.17 & 32.99 & 33.47 & 35.15 \\
\hline \multirow{4}{*}{14} & $c_{c u}(\mathrm{kPa})$ & 23.94 & 35.95 & 26.09 & 39.14 & 22.19 & 34.06 & 24.30 & 36.51 \\
\hline & $c_{c u}^{\prime}(\mathrm{kPa})$ & 21.35 & 31.56 & 23.24 & 35.35 & 19.60 & 29.08 & 20.67 & 32.80 \\
\hline & $\varphi_{c u}\left(^{\circ}\right)$ & 17.02 & 19.21 & 18.08 & 20.66 & 15.17 & 18.30 & 17.51 & 20.24 \\
\hline & $\varphi_{c u}^{\prime}\left({ }^{\circ}\right)$ & 38.18 & 39.72 & 45.77 & 46.31 & 36.93 & 37.13 & 39.77 & 40.27 \\
\hline \multirow{4}{*}{28} & $c_{c u}(\mathrm{kPa})$ & 30.53 & 45.85 & 33.27 & 49.92 & 28.30 & 43.44 & 30.98 & 46.56 \\
\hline & $c_{c u}^{\prime}(\mathrm{kPa})$ & 27.22 & 40.24 & 29.63 & 45.08 & 25.00 & 37.08 & 26.37 & 41.83 \\
\hline & $\varphi_{c u}\left(^{\circ}\right)$ & 18.44 & 20.43 & 19.63 & 21.39 & 16.07 & 19.43 & 18.38 & 21.75 \\
\hline & $\varphi_{c u}^{\prime}\left({ }^{\circ}\right)$ & 44.48 & 45.30 & 46.80 & 47.10 & 42.98 & 43.94 & 43.72 & 45.98 \\
\hline
\end{tabular}

Accordingly, the effect of friction component will be weakened when the size of the aggregate produced by the damage of cemented structure becomes smaller, whereas all these will be gradually improved due to the increase of cement content or curing time.

\section{Conclusions}

The strength characteristics of cement treated and expanded polystyrene mixed lightweight of waste soil from the construction site of a Yangtze River bridge in China were investigated, regarding the compaction test, the unconfined compressive test, and the traditional triaxial test. The results were analyzed and the influence factors were evaluated. The main conclusions are as follows:

(1) The cement treated and expanded polystyrene mixed lightweight is a kind of mixed material suitable for subgrade filling, and its real strength actually comes from the structure formed by cement hydration and cementation. According to the compaction test, the waste soil lightweight can be controlled according to the degree of compaction, but the influence of different cement ratio can be ignored.
(2) Under the present proportions and test conditions, the unconfined compression strength increases with increasing cement content, and a well exponential relation can be obtained. The unconfined compression strength also increases with increasing curing time, and a logarithmic relation can be obtained. The strength performance of lightweight will be reduced due to the increase in EPS beads usage.

(3) The unconfined compression strength increases rapidly within the original 28 days of curing time. Different waste soil lightweight has different strength properties; the fine sand lightweight has higher strength than the muddy clay lightweight, which is suitable for different cement contents and EPS beads addition. In terms of strength, this kind of lightweight mixture is feasible as a kind of subgrade filler material.

(4) The lightweight material originated from the two kinds of waste soil is a strain-hardening material, and its strength increases with the increase of confining pressure. The stability of the mixture is good, and the cohesion and the internal friction angle can be obtained by the common triaxial test. In theory, this 
kind of waste material has great potential for recycling, but the premise is that other supporting tests also need to be conducted.

\section{Data Availability}

The experimental data used to support the findings of this study are included within the article. And other previously reported data supporting this article are from the outcomes of publicly published papers. Those prior studies (and datasets) have been cited at relevant places within the text as references. The authors agree to share the data of this paper and allow other researchers to verify the results of this article, replicate the analysis, and conduct secondary analyses.

\section{Conflicts of Interest}

The authors declare that they have no conflicts of interest.

\section{Acknowledgments}

The authors acknowledge and appreciate the financial support provided by the National Natural Science Foundation of China (Project nos. 51508279, 51478054, and 51508278) and the Jiangsu Provincial Natural Science Fund Projects (BK20150885). Moreover, the work was also supported by the Open Fund of Key Laboratory of Road Structure and Material of Ministry of Transport (Changsha University of Science and Technology, kfj180303), the Ministry of Housing and Urban-Rural Development of the People's Republic of China (2018-K4-008) and the Open Fund of National-Local Joint Laboratory of Engineering Technology for Long-term Performance enhancement of Bridges in Southern District (Changsha University of Science \& Technology).

\section{References}

[1] J. Peng, J. Zhang, J. Li, Y. Yao, and A. Zhang, "Modeling humidity and stress-dependent subgrade soils in flexible pavements," Computers and Geotechnics, vol. 120, Article ID 103413, 2020.

[2] J. Zhang, J. Peng, L. Zeng, J. Li, and F. Li, "Rapid estimation of resilient modulus of subgrade soils using performance-related soil properties," International Journal of Pavement Engineering, pp. 1-8, 2019.

[3] J. Zhang, J. Peng, W. Liu, and W. Lu, "Predicting resilient modulus of fine-grained subgrade soils considering relative compaction and matric suction," Road Materials and Pavement Design, pp. 1-13, 2019.

[4] E. Vitale, D. Deneele, G. Russo et al., "Chemo-mechanical behaviour of lightweight cemented soils," Acta Geotechnica, vol. 15, no. 4, pp. 933-945, 2019.

[5] X. Q. Zhao, G. Zhao, J. W. Li, and P. Zhang, "Unconfined compressive strength property and its mechanism of construction waste stabilized lightweight soil," Geomechanics and Engineering, vol. 19, no. 4, pp. 307-314, 2019.

[6] W. Lu, L. Miao, J. Zhang, Y. Zhang, and J. Li, "Characteristics of deformation and damping of cement treated and expanded polystyrene mixed lightweight subgrade fill under cyclic load," Applied Sciences, vol. 9, no. 1, p. 167, 2019.
[7] A. J. Puppala, P. Ruttanaporamakul, and S. S. C. Congress, "Design and construction of lightweight EPS geofoam embedded geomaterial embankment system for control of settlements," Geotextiles and Geomembranes, vol. 47, no. 3, pp. 295-305, 2019.

[8] T. Frydenlund, "Expanded polystyrene-A lighter way across soft ground," International Report No. 1502, Norwegian Road Research Laboratory, Oslo, Norway, 1991.

[9] H. Gao, J. Liu, and H. Liu, "Geotechnical properties of EPS composite soil," International Journal of Geotechnical Engineering, vol. 5, no. 1, pp. 69-77, 2011.

[10] M. D. Li, K. J. Wen, and L. L. Tian, "Mechanical properties of expanded polystyrene beads stabilized lightweight soil," Geomechanics and Engineering, vol. 13, no. 3, pp. 459-474, 2017.

[11] H. Liu, A. Deng, and J. Chu, "Effect of different mixing ratios of polystyrene pre-puff beads and cement on the mechanical behaviour of lightweight fill," Geotextiles and Geomembranes, vol. 24 , no. 6, pp. 331-338, 2006.

[12] W. Lu, L. Miao, F. Wang, J. Zhang, Y. Zhang, and H. Wang, "A case study on geogrid-reinforced and pile-supported widened highway embankment," Geosynthetics International, pp. 1-14, 2019.

[13] L. Miao, F. Wang, J. Han, W. Lv, and J. Li, "Properties and applications of cement-treated sand-expanded polystyrene bead lightweight fill," Journal of Materials in Civil Engineering, vol. 25, no. 1, pp. 86-93, 2013.

[14] F. Wang and L. Miao, "A proposed lightweight fill for embankments using cement-treated Yangzi river sand and expanded polystyrene (EPS) beads," Bulletin of Engineering Geology and the Environment, vol. 68, no. 4, pp. 517-524, 2009.

[15] K. Onishi, Y. Tsukamoto, R. Saito, and T. Chiyoda, "Strength and small-strain modulus of lightweight geomaterials: cement-stabilised sand mixed with compressible expanded polystyrene beads," Geosynthetics International, vol. 17, no. 6, pp. 380-388, 2010.

[16] S. Zarnani and R. J. Bathurst, "Influence of constitutive model on numerical simulation of EPS seismic buffer shaking table tests," Geotextiles and Geomembranes, vol. 27, no. 4, pp. $308-312,2009$.

[17] H. M. Gao, X. Li, Z. H. Wang, A. W. Stuedlein, and Y. Wang, "Dynamic shear modulus and damping of expanded polystyrene composite soils at low strains," Geosynthetics International, vol. 26, no. 4, pp. 436-450, 2019.

[18] W. H. Lu, Y. X. Zhang, W. Z. Liu, C. Liu, and H. B. Wang, "Evaluation of geomembrane effect based on mobilized shear stress due to localized sinking," Advances in Civil Engineering, vol. 2019, Article ID 4942578, 11 pages, 2019.

[19] M. Vela Silveira, A. V. Calheiros, and M. D. T. Casagrande, "Applicability of the expanded polystyrene as a soil improvement tool," Journal of Materials in Civil Engineering, vol. 30, no. 6, Article ID 06018006, 2018.

[20] ASTM D2487-11, Standard Practice for Classification of Soils for Engineering Purposes, American Society for Testing Materials, West Conshohocken, PA, USA, 2011. 